\title{
Canada needs paradigm shift in public health nutrition
}

$\mathrm{T}$ he refrain was common: lots of talk, little action. Whether regulating trans fats and salt, adequately labelling foods, or taxing potato chips and other calorie-rich snacks, initiatives around the world are sparse and successes sparser still, delegates to an international conference on public health nutrition were told Oct. 22-23 in Ottawa.

Perhaps dimmer still is the situation in Canada, where disease-prevention efforts are often even more modest than those of Western counterparts and hampered by lack of political will, proverbial jurisdictional wrangling between the federal and provincial governments, an emasculated Public Health Agency of Canada, and conflicted bureaucracies that are simultaneously mandated to promote industrial development and health.

The Canadian situation is certainly checkerboard in nature, says conference organizer and Centre for Science in the Public Interest national coordinator Bill Jeffery. While there have been constructive initiatives, such as schoollunch programs, a trans fat ban in Calgary restaurants and Quebec's regulations on food advertising to children, there's still "a need for Canadian governments to aspire to better things."

"There's ample evidence that people are dying by the tens of thousands that the experts have demonstrated we all know the causes of, [such as] reducing diet-related heart disease by reducing sodium intake and saturated fat intake, reducing colorectal cancer by increasing fruit and vegetable consumption, yet we don't have public health authorities that are prepared to press government down in that direction and take direction on their own."

The relative merit of regulatory, educational and fiscal approaches to promoting health through nutrition was a recurrent thread of debate in the gathering of public health officials, nutrition-

\section{Front of pack "traffic light" coding}

Proponents call it an "intuitive" system.

Most everyone, after all, associates green with go, amber with caution and red with stop, so it isn't that great a leap to think that, in relation to certain nutrients in foods, green means low, amber means medium and red means high.

Consumer testing also indicated that the United Kingdom's traffic light system for colour-coding composite, processed foods - a voluntary code that has slowly been adopted since first advocated in 2005 - was far less confusing, says Rosemary Hignett, head of the UK Food Standards Agency's nutrition division.

Traditional back-of-pack nutrient labelling is ineffective, Hignett says. "Consumers found it inaccessible. People couldn't relate the numbers to a benchmark, either in their head or elsewhere, so they couldn't judge whether a figure, say a 7, was a high number or a low number, so they didn't know how to use it in practice."

The traditional nutrient labels remain on foods sold in the UK. But in addition, consumers are being provided with front-of-package traffic light labels in 4 categories: fat, saturated fat, sugars and salt.

The green and amber boundaries were determined by existing UK and European Commission regulations governing health claims, such as low fat or low sugar. For example, a product gets a green light for sugars if it has less than $5 \mathrm{~g} / 100$ $\mathrm{g}$. It gets an amber light for between 5-12 $\mathrm{g}$ and a red light for more than $12.5 \mathrm{~g}$. Specific levels for other categories are available at www.eatwell.gov.uk/foodlabels/trafficlights/.

In addition to the per $100 \mathrm{~g}$ criteria, there are "per portion" criteria for the traffic lights, based on an adult's recommended daily intake for the substance. If a food contributes more than $30 \%$ of the recommended daily intake for fat, saturates or sugars, or more than $40 \%$ for salt, it gets a red light in that category. But the agency plans to "ratchet down" the calculations for salt intake in the near future, Hignett says.

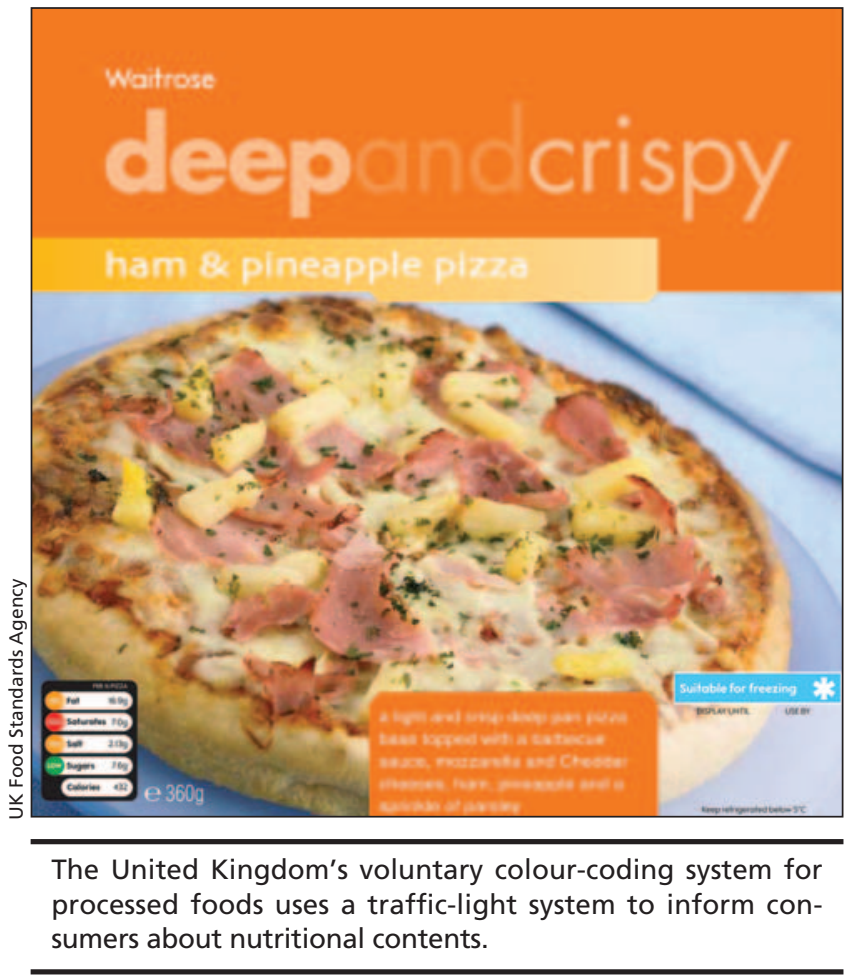

In some cases, firms have included a "caloric" percentage in their traffic light box. That typically indicates the number of calories per serving of the product, and in some cases, the share of an adult's overall recommended daily caloric intake that will be gobbled up if someone eats 1 serving of the product.

Label size is left to the discretion of the manufacturers.

The regime is entirely voluntary but Hignett says that 8 major food retailers, 26 manufacturers and 1 restaurant chain have clambered aboard the traffic light train. That translates into about $40 \%$ of all composite, processed foods sold in Britain. "It's a good portion of the market." 
ists, dieticians, industry representatives and health advocates.

Typical was the discussion on attempts to limit trans fats in processed foods. Denmark imposed strict regulatory limits in 2004 and the results have been remarkable, reported Jens Therkel Jensen, deputy head of the Ministry of Food, Agriculture and Fisheries' Veterinary and Food Administration nutrition division. "An estimated 400-500 lives per year have been saved" within the country's population of 5 million.

Educational campaigns proved entirely ineffective in reducing trans fat use in the United States' largest city, argued Gail Goldstein, deputy director of the New York City Department of Health and Mental Hygiene's cardiovascular disease prevention and control program, while describing a multiyear effort to ban trans fats in cooking oils. But regulations were subsequently introduced and have proven effective. About a dozen other cities have since followed suit. California recently became the first state to ban the use of trans fats in restaurants, commencing in 2010, and in baked goods, commencing in 2011.

By contrast, the United Kingdom has adopted an educational approach, largely using labelling and moral suasion to persuade food producers, retail-

Hignett explained that while the agency is entirely independent (unlike the Public Health Agency of Canada, which reports to the health ministry) and has no competing obligation to promote food industry development, enforcement is achieved entirely through publicity. The agency's carrot and stick are essentially the same: public praise or censure.

Delegates were told nutritional labeling endeavours in Europe are made even more problematic by the fact that European Union nations are limited in their individual capacity to impose labeling standards. The EU is now developing new labeling guidelines for all its members, but those aren't expected to be completed for 2 years.

The overall efficacy of current efforts to promote health through nutritional labelling was also questioned as several delegates indicated consumers often find the nutritional data on packaging extremely confusing. By contrast, studies indicate "caloric content" labelling has been a somewhat effective tool in influencing consumer decisions in fast-food restaurants.

Hignett indicated the UK is now studying whether the colour-coded "traffic light" approach it adopted in 2005 in which red, amber and green warnings are placed on the front of food packages

\section{"An unregulated market is doing to human health what it has done to the US economy" - Dr. Walter Willett, Harvard School of Public Health.}

ers and consumers to "voluntarily" reduce fats, salt and sugar, said Rosemary Hignett, head of the UK Food Standards Agency's nutrition division. Hignett indicated that about $70 \%$ of companies have "committed publicly" to doing so in the future but the restaurant industry has been a notable holdout.

Several delegates noted the efficacy of the UK approach is compromised by the modest targets set for trans fat, salt and sugar reduction, while others queried whether the Foods Standards Agency has adequate regulatory authority to actually impose changes. by category, for example, red light for salt if sodium content is higher than recommended daily intake (see page 1259) - can be used to identify whether any specific food and its aggregate contents could be labeled healthy. Unhealthy foods would get a red light.

A similar aggregated or so-called "holistic" approach is being unveiled within supermarkets in the northeastern United States. Developed by Yale-Griffin Prevention Research Center director Dr. David Katz, it uses an algorithm to compare individual products, such as brands of peanut butter, and rate them on a scale of 1-100 (see page 1261).

But whether consumers are more prone to making "healthy" choices within such a rating system or more influenced by price considerations is entirely debatable, several delegates noted.

In fact, the general efficacy of achieving health benefits through fiscal measures, such as junk food, drive through or other form of fat taxes, is unproven, argued economists Jorgen Dejgaard Jensen of the University of Copenhagen's Institute of Food and Resource Economics, Kathy Baylis of the University of Illinois and Mike Rayner of the British Heart Foundation Health Promotion Research Group during a session on food tax reform.

Econometric research hasn't been conducted to verify whether any form of fat taxes actually yield anything other than additional government revenues or, conversely, whether significant health benefits accrue from reducing taxes on healthy foods, they said.

Others saw the need for structural reforms and political action to promote public health nutrition.

The Public Health Agency of Canada, and its provincial counterparts, must develop "population health nodes" with responsibility for nutritional measures and the reduction of health disparities between population groups, particularly Canada's aboriginal community, said Senator and former Ottawa Heart Institute director Dr. Wilbert Keon, while repeatedly extolling the virtues of Cuba's polyclinic system and its emphasis on wellness and prevention.

Dr. Walter Willett, chair of the Harvard School of Public Health's department of nutrition, argued that there is a pressing need for tougher regulation in such areas as: advertising to children; labelling; foods available in schools; salt content within foods; and foods served in public institutions such as hospitals. "An unregulated market is doing to human health what it has done to the US economy" during the recent credit crisis, Willett said.

Among other issues raised was the lack of nutritional training within the core curriculum of Canada's medical schools. - Wayne Kondro, CMAJ

DOI:10.1503/cmaj.081755 


\section{Forget pie, try pi}

Call it a health algorithm for processed foods or just plain mathematical eats.

Arguing that current nutrient labels on processed foods are misleading and meaningless, if not incoherent, University of Yale Adjunct Associate Professor of Public Health Dr. David Katz has crafted a mathematical formula to calculate the relative health of foods on a scale of 1-100.

Simply put, the higher the number, the higher the nutritional value.

The scoring system is being unveiled in roughly 125 supermarkets (including Price Chopper) in the northeastern and midwestern United States this fall. It will see nutritional scores posted on shelves - right next to price tags. Another 5000 stores are slated to introduce the system by the end of next year.

The system allows consumers to make choices between and within major food groups, by comparing the nutritional values, for example, of ground beef and salmon, as well as choices between different brands of products such as soups.

Katz says the need for improved labelling is self-evident. "If the information on a food package is intended to help the average consumer tell how good that product is for them and their families and whether or not it's better for them than the product sitting next to it, then it fails miserably. ... It requires an enormous amount of heavy lifting by the consumer."

The NuVal ${ }^{\mathrm{TM}}$ Nutritional Scoring System (www.nuval.com) uses the data on the nutrition facts panel of a packaged food to essentially quantify the contained amounts of about $30 \mathrm{nu}-$ trients. Basically, it creates a nutrientcontent profile of an individual product and runs it through an Overall Nutritional Quality Index (ONQI) algorithm.

The nutrients measured include socalled "good" ones such as vitamins, minerals fibre, folates and Omega-3 fatty acids; and those that have unfavourable health effects, such as salt, trans fat, saturates, sugars and choles-

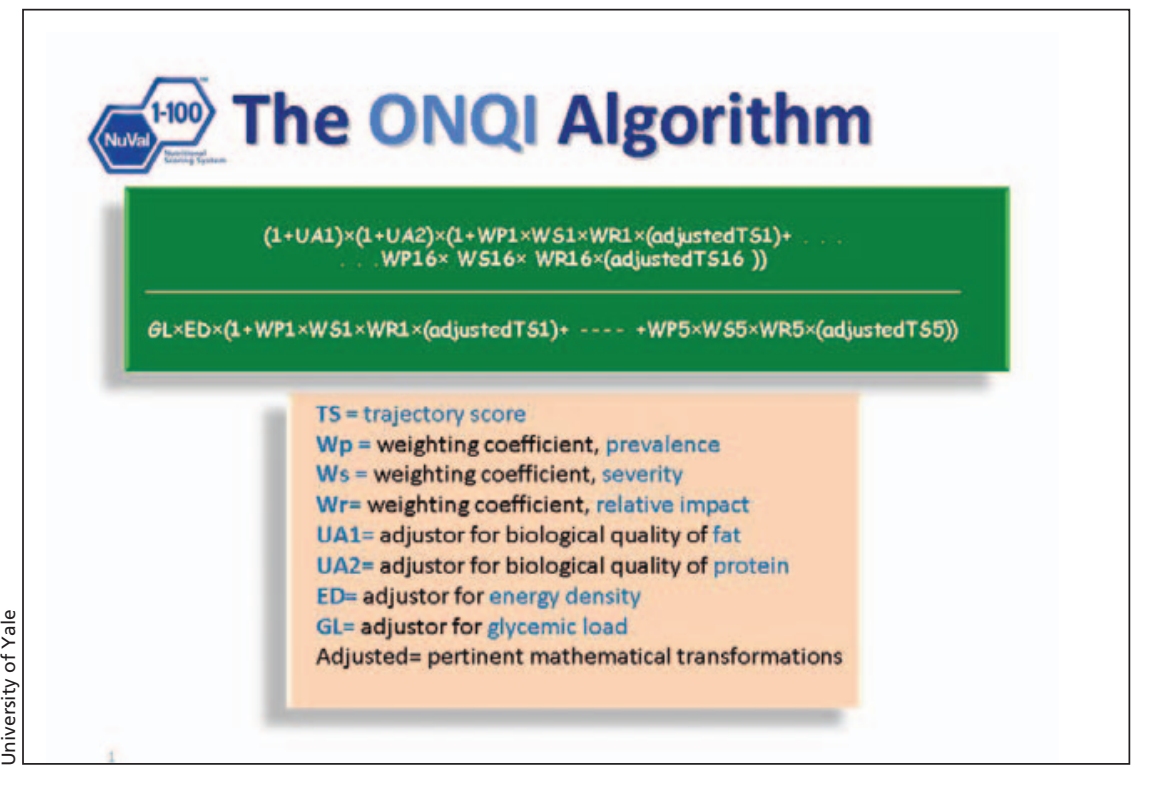

A "simplified" version of the algorithm used to determine whether foods are healthy under the NuVal'TM Nutritional Scoring System.

terols. It also factors in things such as protein quality, fat quality, glycemic load and energy density.

Nutrients that have beneficial effects are placed in the algorithm's numerator, while those that are unfavourable are placed in the denominator.

Both are "weighted" according to their health impact, Katz says. "What we did was enter into the algorithm all of those nutrients for which there is a solid base of scientific evidence that these make a difference. So, for example, Omega-3 fat: why is it good for us? Is it good for us just because we like the way that it rolls off our tongue? No. It's good for us for specific reasons. It prevents cardiac dysrhythmias. It reduces the risk of sudden cardiac death. It seems to have a favourable influence on the lipid panel. Potassium, magnesium: why are they good for us? So what we did was for all of the nutrients which were entered, whether good or bad, we associated them with the conditions for which they were most intricately linked. We asked the question, how common are these conditions within the population? How serious are they? Are they a minor inconvenience like a dermatosis or are they a serious threat to life and limb, like heart disease and cancer? And what is the strength of association between the nutrient and conditions? So, for example, both dietary cholesterol and fat are linked to heart disease. But for dietary cholesterol, it's a very weak link, whereas trans fat makes a significant contribution. The ONQI takes all that into account."

After all the math, the end result is an "easy to use," consumer-friendly final tally, Katz says.

Katz says derivatives of the algorithm could also easily be used to rate foods according to disease, such as diabetes or cardiovascular disease, or by objective, such as weight management.

To use the algorithm, supermarkets pay a licensing fee to $\mathrm{NuVal}$ LLC, a joint venture of Topco Associates LLC and Griffin Hospital, a teaching hospital affiliated with the Yale University School of Medicine.

Licensing fees depend on the size of the store (or chain), Katz says. "For a chain with thousands of stores, it would be millions of dollars. For a chain with 30 stores, it would be in the 5-6 figure range."

Studies of consumer reaction to the index have not yet been undertaken. 